\title{
Escherichia coli Quinolinate Synthetase Does Indeed Harbor a [4Fe-4S] Cluster
}

\author{
Robert M. Cicchillo, Loretta Tu, Jeffrey A. Stromberg, Lee M. Hoffart, Carsten Krebs*, and Squire J. \\ Booker*
}

Department of Biochemistry and Molecular Biology and Department of Chemistry. The Pennsylvania State University, University Park, Pennsylvania 16802

\section{Experimental}

\section{Supporting Information}

General Information: Pyridine, bovine serum albumin (BSA), and $N$-methyl- $N$ trimethylsilyltrifluoroacetamide (MSTFA) were purchased from Pierce (Rockford, IL). All other reagents were purchased from Sigma-Aldrich (St. Louis, MO) and were used without any further purification.

Determination of Protein Concentration: The protein concentration was determined by the method of Bradford using a commercially available reagent (Pierce, Rockford, IL) in combination with BSA (fraction V). Using quantitative amino acid analysis it was determined that the Bradford assay, performed as such, gives an accurate determination of NadA concentration with no need for a normalization factor.

Expression of the nadA gene: The nadA gene was cloned by PCR into plasmid pET-28A (confers kanamycin resistance)-which is IPTG-inducible and under the control of the T7 promoter-such that the protein is produced with an N-terminal hexahistidine tag that is separated from the natural N-terminal methionine residue by a linker of 10 amino acids. The plasmid was transformed into E. coli BL21(DE3) that also harbored plasmid pDB1282 (confers ampicillin resistance), which contains the genes of the $A$. vinelandii isc operon under the control of an arabinose-inducible promoter. The isc-related genes were induced first by addition of arabinose $\left(0.05 \%\right.$ final concentration at an $\mathrm{OD}_{600}$ of 0.3 , followed by induction of the $n a d A$ gene by addition of IPTG $(200 \mu \mathrm{M}$ final concentration $)$ at an $\mathrm{OD}_{600}$ of 0.6.

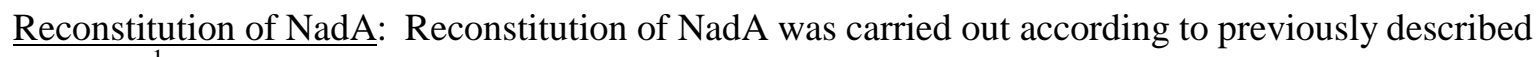
methods. ${ }^{1}$

Assay for Quinolinic Acid: The time-dependent formation of quinolinic acid was measured directly by HPLC. The assay contained in a final volume of $1.3 \mathrm{~mL}, 50 \mathrm{mM} \mathrm{Na}-\mathrm{HEPES}, \mathrm{pH} 7.5,25 \mathrm{mM}$ aspartate, $25 \mathrm{mM}$ fumarate, $25 \mu \mathrm{M}$ FAD, $1 \mathrm{mM}$ dihydroxyacetone phosphate, $100 \mathrm{mM} \mathrm{KCl}, 15 \mu \mathrm{M}$ reconstituted $\mathrm{NadA}, 15 \mu \mathrm{M} \mathrm{NadB}$, and $1 \mathrm{mM} L$-tryptophan. The reaction was initiated by addition of NadB after incubation of the other components of the assay mixture at $37^{\circ} \mathrm{C}$ for $3 \mathrm{~min}$. For the quantification of quinolinic acid, $200 \mu \mathrm{L}$ aliquots of the assay mixture were removed at designated times and added to 10 $\mu \mathrm{L}$ of $2 \mathrm{~N} \mathrm{H}_{2} \mathrm{SO}_{4}$ to quench the reaction. Precipitated proteins were pelleted by centrifugation at 14,000 $\mathrm{rpm}$ for $25 \mathrm{~min}$. $25 \mu \mathrm{L}$ of the supernatant was injected directly onto the HPLC. Under previously described conditions, ${ }^{1}$ quinolinic acid had a retention time of $4.3 \mathrm{~min}$. Authentic quinolinic acid (Sigma) was used to generate a standard curve from 5-500 $\mu \mathrm{M}$. From the standard curve, the amount of quinolinic acid was determined at $2,5,10,15$, and 20 min.

GC-MS Analysis of Quinolinic Acid: Assays were carried out as described above. Quinolinic acid produced at each time point was isolated by HPLC, and the combined solutions were removed in vacuo. Pyridine $(50 \mu \mathrm{L})$ and MSTFA $(100 \mu \mathrm{L})$ were added to the remaining pellet, and the mixture was heated at $100{ }^{\circ} \mathrm{C}$ for $1 \mathrm{~h}$. This results in the formation of two trimethylsilyl (TMS) derivatives, one for quinolinic acid and one for nicotinic acid. The derivatized products were injected onto a Shimadzu GCMS-QP5000 without further purification. Sample introduction was via splitless injection onto a XTI-5 column (30 $\mathrm{m} \mathrm{x}$ 
$0.25 \mu \mathrm{m}$ film thickness; Restek Corporation). The following GC conditions were used: injection temperature, $250^{\circ} \mathrm{C}$; initial temperature, $40{ }^{\circ} \mathrm{C}$ for $2 \mathrm{~min}$ which was increased to $80{ }^{\circ} \mathrm{C}$ at $5{ }^{\circ} \mathrm{C} \mathrm{min}{ }^{-1}$. The temperature was then ramped at $10{ }^{\circ} \mathrm{C} \min ^{-1}$ to $250{ }^{\circ} \mathrm{C}$. The following ions were monitored for the trimethylsilyl derivative of quinolinic acid: $311,296,194,147,73$, and $45 \mathrm{~m} / \mathrm{z}$. Nicotinic acid trimethylsilyl ester fragments to yield the following major ions: $195,136,106,78$, and $51 \mathrm{~m} / \mathrm{z}$. The respective ions produced from the two derivatives were observed using single ion monitoring (SIM).

Preparation of Mössbauer and EPR Samples: Samples to be analyzed by Mössbauer and EPR spectroscopies were prepared inside of the anaerobic chamber and contained 400-900 $\mu \mathrm{M}$ NadA. Samples (400 $\mu \mathrm{L}$ final volume) to be analyzed by Mössbauer spectroscopy were frozen with liquid nitrogen inside of small plastic cups. For characterization by EPR, the samples $(250 \mu \mathrm{L}$ final volume $)$ were first treated with $2 \mathrm{mM}$ sodium dithionite at ambient temperature for $\sim 2 \mathrm{~min}$, placed in EPR tubes $(2 \mathrm{~mm}$ i.d.), and frozen in liquid nitrogen. All steps associated with preparing the samples were conducted inside of a Coy Laboratory Products (Grass Lake, MI) anaerobic chamber $\quad\left(<\quad \begin{array}{llllll} & \text { ppm }\end{array}\right.$ $\mathrm{O}_{2}$ ).

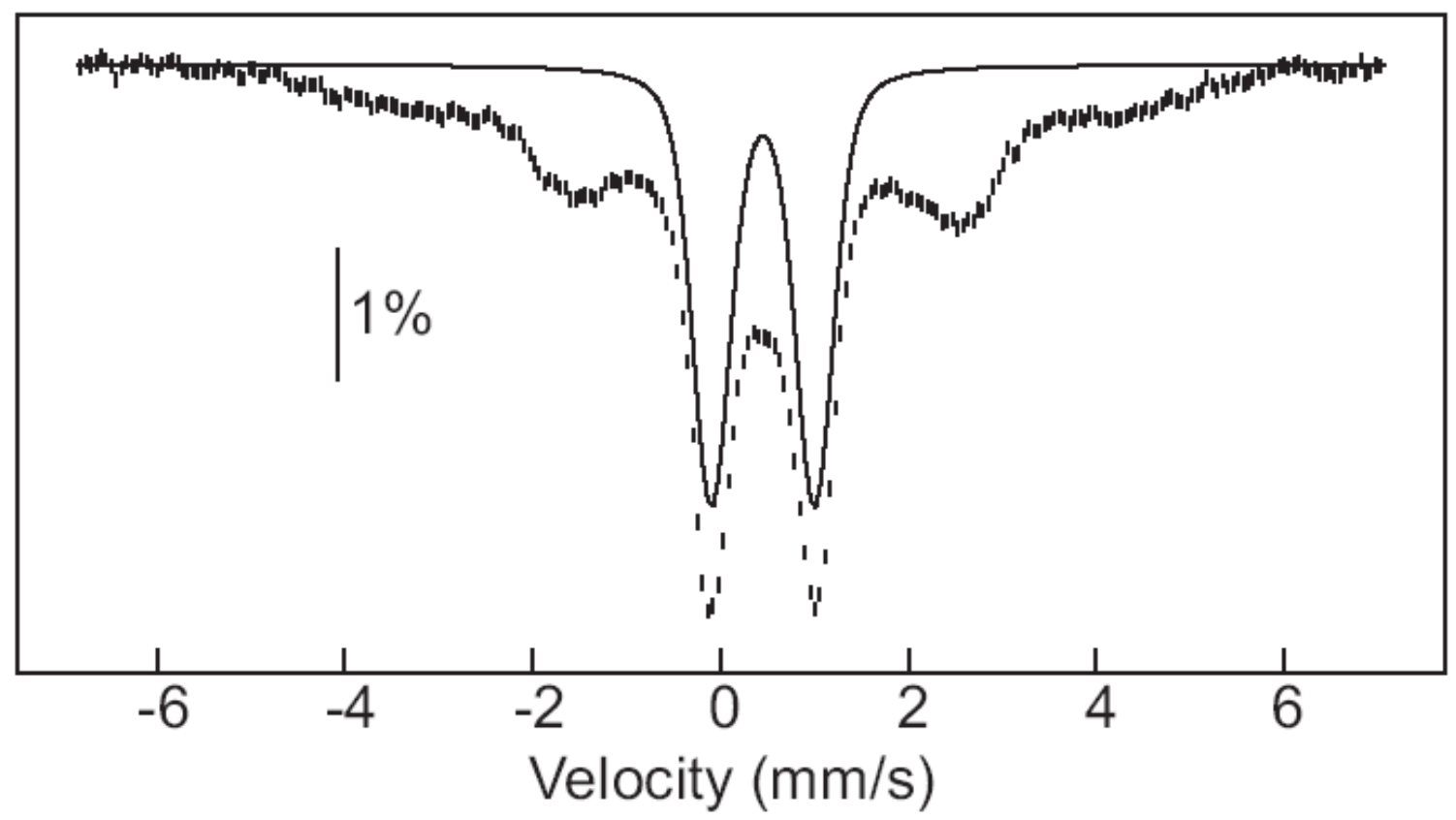

Figure S1. 4.2 K Mössbauer spectrum of reconstituted NadA recorded in a parallel magnetic field of $40 \mathrm{mT}$. The solid line is a simulation of the $[4 \mathrm{Fe}-4 \mathrm{~S}]^{2+}$ cluster using the parameters determined from the as-isolated $\operatorname{NadA}\left(\delta=0.45 \mathrm{~mm} / \mathrm{s}, \Delta \mathrm{E}_{\mathrm{Q}}=1.10 \mathrm{~mm} / \mathrm{s}\right)$, corresponding to $40 \%$ of the total intensity of the experimental spectrum. 


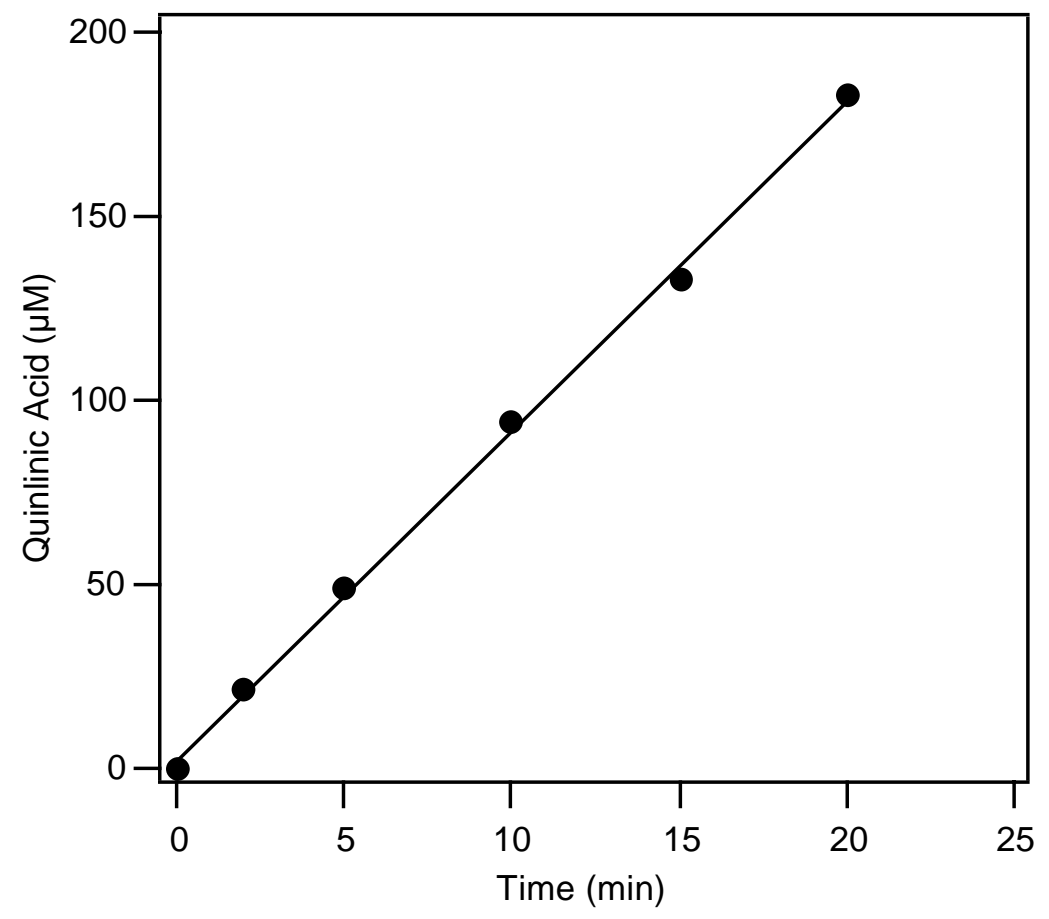

Figure S2. Time-dependent formation of quinolinic acid catalyzed by reconstituted NadA.

(1) Cicchillo, R. M.; Iwig, D. F.; Jones, A. D.; Nesbitt, N. M.; Baleanu-Gogonea, C.; Souder, M. G.; Tu, L.; Booker, S. J. Biochemistry 2004, 43, 6378-6386 